\title{
Demand for Generic Competences in the Labour Market: Reliability of Workers' Perception
}

\author{
Ashfaque Ahmad SHAH (Corresponding author) \\ Centre for Economics of Education, Department of Education \\ University of Sargodha, 40100 Sargodha, Pakistan
}

Tel: 92 - (0)48 - 923-0553 E-mail: multanxa@gmail.com

Uzma SHAHZADI

Centre for Economics of Education, Department of Education

University of Sargodha, 40100 Sargodha, Pakistan

Tel: 92 -(0)48 - 923-0553 E-mail: uzmaadawood@gmail.com

Jean-Jacques PAUL

IREDU UMR 5225 CNRS/Université de Bourgogne

Pôle AAFE-Esplanade Erasme-BP 26513, F - 21065 Dijon Cedex, France

Tel: 33-(0)38-039-5450Ｅ-mail: paul.jeanjacques@gmail.com

Received: January 23, 2012

Accepted: February 10, 2012 Published: May 1, 2012

doi:10.5539/ijef.v4n5p227

URL: http://dx.doi.org/10.5539/ijef.v4n5p227

\begin{abstract}
This study deals with the question of reliability of assessment of required competences. Required competences have been assessed by young knowledge workers in the labour market. Question is 'to what extent their assessment of required competences is reliable, if it is reliable'. We used the data set of Reflex project which was carried out under the $6^{\text {th }}$ framework programme of European Union. We employed ordered probit, and OLS regression. The analyses have been realised in SPSS and Stata. We employed coherence and consistency parameters in order to draw conclusions from our findings. We found nothing contradictory to our reliability hypothesis. We feel confident to say that knowledge workers' assessment of (required) competences is found to be, in Popperian terms, reliable to a modest extent. The fact that the respondents knew, at the time of survey, that they will not be harmed, could be regarded as a limitation to this study. We have explored only the required level of competences in this study.
\end{abstract}

Keywords: Reliability, Assessment, Generic competence, Labour market, Knowledge workers, Ordered probit

\section{Introduction}

The aim of higher education is to sustain learning society, [1] where labour market relevant knowledge and skills as well as a set of personal competences are considered as crucial [2]. The reason is that workers with sufficient and up-to-date competences are more productive and have more potential to remain employed [3]. Labour market oriented competences are highly required and highly remunerated. Recent literature demonstrates heightened interest to study (acquired as well required) competences.

Although strong demand of competence in the labour market has been confirmed [4], yet there are some concerns over the assessment of required competences. For a detailed account we would like to invite the inquisitive readers to consult the Reflex Working Paper 2 [5]. This document discusses various aspects of acquired as well as required competences' assessment. We find a dual advantage to study the assessment of required competences. First, the main reason to support this method is a conviction that self-reported skill requirements are less prone to response bias than self assessments of own skills [6] (quotes [7]). Second, researchers alike [8] think that it helps studying the self assessment of acquired competences. Some researchers have therefore proposed the use of self reported skill requirements in jobs as indicators of the actual skills of the holder of those jobs (see e.g. [9]. 
This study examines the reliability of assessment of required competences by the young knowledge workers. We would like to mention that the higher education graduates and the young knowledge workers are the same individuals in our data set. This is only the preferred use of the two expressions. We prefer to call individuals the higher education graduates while addressing the problem of self assessment of acquired competences; and the young knowledge workers while studying assessment of the required competences. We will be studying the reliability of assessment of required competences by the young knowledge workers. Following is the research question: To what extant is knowledge workers' assessment of required competence reliable?

Reflex data set comprising about 40,000 graduates from fifteen countries is available for the analysis in order to provide the substance of statistical analyses for this paper.

\section{Selecting the Variables}

First step in this endeavour is to identify the subcategories upon which knowledge workers are distributed. More precisely, it is "missing word" to find some common characteristics (nature and/or experience) in order to classify young knowledge workers. The experience concerning with their profession, we think, could be a reasonable criterion to categorise the young knowledge workers. We identify three variables directly related to this experience criterion. These are:

1. Total Monthly Income (in Euros)

2. Appropriate Education Level for Current Job

3. Time to be Expert in Current Job

These three variables provide us young knowledge workers' categorisation criteria. Total Monthly Income (in Euros) is a continuous variable. We categorise this into eight subcategories. Appropriate Education Level for Current Job has four subcategories. Time to be Expert in Current Job has six categories but we merged first three categories (thus making total four subcategories) in order have more clear picture. The details we will discuss in the ensuing paragraphs. We also include gender and country as control variables in this list.

The variable of main focus is competence which is considered as dependent variable. We have 19 competences in the data set. We select twelve of them. Young knowledge workers were asked to rate their competence level on a rating scale of seven. Next step is to describe all these variables. For the detailed description of the variables of interest is given in the Appendix A.

\section{Basic Statistics}

The above mentioned variables are described here through descriptive statistics. These variables are: Country, Total Monthly Income (in Euros), Appropriate Education Level for Current Job and Time to be Expert in Current Job and Gender. Table 1 contains percentage participation of the knowledge workers being included in the analyses. We have excluded invalid observations. Total 28690 knowledge workers from all fifteen countries are included in the analyses. The male-female ratio is $45-55$ percent respectively. The numbers of observations for rest of variables are about 28000 .

\section{Insert Table 1 Here}

Table 2 describes the relevant variables through their basic statistics. For example, the average income is about 2300 Euros with a standard deviation of 1500 Euros and mean time to be expert is observed to be 3 years with a standard deviation one year.

\section{Insert Table 2 Here}

\section{Required Level of Competences}

On the bases of young knowledge workers' responses we calculated the mean values of competences for the whole data. This table keeps mean values of all nineteen competences for the total sample in descending order.

Insert Table 3 Here

The mean values for the required level of competences are recorded in Table 3. Competences have been rearranged in descending order of their mean values. We observe a cut point of four in the order of mean values in this table which is dividing the whole set of 19 competences into two subsets. One subset has its means more than, and the other less than, the cut point of five. Although there are eleven competences which have their mean values above the cut point but we select first 12 competences and name this as Subset-I. The other one is named as the Subset-II. We will use the Subset-I for further analyses. 


\section{Research Hypothesis}

We assume that young knowledge workers with similar characteristic (i.e. knowledge worker experience) are homogeneously assigned to their respective subcategories. We expect that the Knowledge workers of the same subcategory will also reflect homogeneity in their independent individual responses concerning their assessment of required competences. Statistically speaking, their inter-group variances should be larger than that of the intra-group. The null hypothesis states that there is no difference among groups' variances.

\section{$H_{0}$ : Knowledge workers of different subcategories do not differ in their assessment of required competence level}

Whereas the alternative hypothesis states that

\section{$H_{A}$ : Knowledge workers of different subcategories do differ in their assessment of required competence level}

Subcategories of knowledge workers are homogeneous in the sense that they are distinct from other subcategories upon certain predefined criteria (i.e. knowledge worker experience). Subcategories do have possessed of knowledge workers with similar characteristics within their respective subcategory. Knowledge workers of similar knowledge worker experience should have declared similar required level of competence. Knowledge workers in each subcategory are distinct and if their assessment of required competences is homogeneous within that very subcategory, then we can consider their assessment as a reliable source of information, until it is falsified.

\section{Analyses}

The variables described above to be used in the analyses in this study are of the nature that they do not permit us to go to calculate neither parametric nor nonparametric ANOVA. We will mention here the resulting coefficient estimates of ordered probit in comparison to the ordinary least squares (OLS) regression coefficient estimates. We will not be extending our analyses to the analyses of variances. Ordered probit is run 12 times for each competence separately with same independent variables. Parallel to this OLS regression is employed for the same set of variables. The outputs of the two are presented in the following tables.

Insert Table 4 and Table 5 Here

The signs of the coefficient estimates allow the direction of change in the probabilities of the extreme outcomes only. Probabilities are relative to the corresponding reference category. The monthly Income has been reconstructed as an ordinal variable; previously it was continuous variable. As it is an objective parameter so we can rely upon this more (compared with the other two variables included in the analysis) for the required level of competences declared by the young knowledge workers. We select a subcategory with lowest income i.e. Monthly Income 1 as a reference. Young knowledge workers from all the subcategories i.e. from Monthly Income 2 to Monthly Income 8, ceteris paribus, have higher probability of having declared a requisition of and a lower probability of not having declared a requisition of greater level of almost all 12 competences in current job. This is exactly what we were expecting. By and large, the monthly income coherently corresponds to the required level of competences. Theoretically, it is believed that higher requirement of competence level is better remunerated. Our results are in agreement to this belief. We have found coherence in theory and practice, which promotes also the suitability of the methodology we have employed. Unexpectedly, required level of competence 8 i.e. Mastery of your own field or discipline, contrary to other competences, reflected uneven coefficient estimates. This could be the case if job demands transversal (generic) competences more than the specific ones; and/or where higher salaries are not necessarily defined on the basis of specific competence [10] and [11].

Highest income (more than four thousand Euros) group reflects that the competence 9 (Ability to write reports, memos or documents), competence 10 (Ability to come up with new ideas and solutions), competence 11 (Analytical thinking), and competence 12 (Willingness to question your own and others' ideas) are not necessarily required in higher levels as compared to their immediate lower income groups. Although it appears strange that these competences, which are undoubtedly, higher in order are lacking in higher income brackets, nevertheless, we can't help reporting this as this is what we observed in our analyses of the data set we are using herein this study.

We have observed similarity in the levels of significance of the coefficients of ordered probit and OLS regression for "Total Monthly Income (in Euros)".

Variable of "Appropriate Sublevel of Education for Current Job" has four subcategories. We chose "Same Education Level" as the reference category. Highly regular and coherent patterns (in theory and practice) are observed for this variable i. e. Appropriate Sublevel of Education for Current Job. Young knowledge workers of subcategory "Higher Education Level", ceteris paribus, have higher probability of having declared a requisition of and a lower probability of not having declared a requisition of greater level of almost all 12 competences in current job. Young knowledge workers of both subcategories "Low Education Level" and "Lower Education Level", ceteris paribus, have lower 
probability of having declared a requisition of and a higher probability of not having declared a requisition of greater level of almost all 12 competences in their current job. In rather simple words we can say that young knowledge workers, who considered that higher education level (compared with reference category i.e. same education level) was appropriate for their current job, declared higher requirement of competence levels accordingly and vice versa.

"Appropriate Sublevel of Education for Current Job" is subjective in its nature. Because these are the young knowledge workers who are supposed to express what is the appropriate required level of education for their current job. However, young knowledge workers are found consistent in their two assessments at two different places. Their first assessment is about the appropriate education level and the second is the required level of competences. Nevertheless, this assessment, which seems subdued with subjectivity, backs up their assessment's reliability.

Similarity in the levels of significance of the coefficients of ordered probit and OLS regression is observable for "Appropriate Education Level for Current Job".

We had six subcategories in the variable "Time to be Expert in Current Job". We reduced first three subcategories into one thus making four subcategories. We leave out the subcategory " 2 Years to be Expert" for reference. This variable, although it is with subjective impression, is reflected also highly regular and coherent patterns (in theory and practice). Young knowledge workers from subcategory " 5 Years to be Expert", ceteris paribus, have higher probability of having declared a requisition of and a lower probability of not having declared a requisition of greater level of almost all 12 competences in current job with respect to the reference category i.e. 2 Years to be Expert. Similar trends are observed for the rest of two subcategories ' 10 Years to be Expert' and 'More Years to be Expert'.

This variable is also subjective like the previous one. These are the young knowledge workers who are to report the required time to get hold of in their current job. In another section of the questionnaire they are rating the required level of the competences. This assessment is also considered subjective. When scrutinized in isolation, both of these questions could be considered as deprived of reliability on account of biasness likelihood. But the intrinsic subjectivity of their responses is minimised when they are juxtaposed. Their responses are found mutually consistent; and in addition to this their responses are coherent in theory and practice. In other words, novices believe in a fewer requirements of competence level compared with the old hands.

We have observed similarity in the levels of significance of the coefficients of ordered probit and OLS regression for "Time to be Expert in Current Job".

These findings are, ceteris paribus, are coherent to what is expected theoretically and what we observe through our analyses.

Although a good discussion can be provoked regarding the interpretation of country and gender estimates mentioned in the tables, but we leave this for they are included in the model as control variables. The reader may look into them for their own interest.

The pseudo $\mathrm{R}^{2}$ (often referred to as [12] pseudo $\mathrm{R}^{2}$ ) varies between 0 and 1 . According to many authors (for example Greene, 2000) there is not natural interpretation of this statistic. However it is observed to be increasing as the fit of the model improves [13]. The $\chi^{2}$ value, with excellent significant difference, helps us to reject the null hypothesis that our model does not have greater explanatory power than an "intercept only" model. We have not mentioned the cutoff points simply because here we do not intend to discuss them as we are not interested in them. We just overlooked this and come to compare ordered probit and OLS regression.

Most of the cases in the tables above are evident that corresponding coefficient estimates of ordered probit and OLS regression resemble each other to a high extent. They do differ sometimes, but this difference is restricted to their immediately next significance levels. We have defined four levels of significance just to give more illumination to the scene. Prime difference between ordered probit and OLS regression is that of cardinal and ordinal values of the numbers which are used to rate the dependent variable. The former considers the ordinal values of the numbers whereas the later takes their cardinal values into consideration in their operations. Although, we have discussed this in some earlier paragraphs of this section prior to discussing the results, however, some deeper insight could be more productive.

We, as rational beings, are convinced to believe (or at least, consider) more in exactitude; and are attracted towards numbers' cardinal value. Moreover, as we know that their cardinal value includes the ordinal (too), we are, intrinsically, dragged more to believe in cardinality of numbers. Since the set of young knowledge workers we are investigating in this study does belong to same population of rational beings, therefore, has no exception. As a researcher we believe (this belief has been intensified through the above analyses) that despite (an imposed) restriction to consider numbers' ordinal value only, we could not help considering their cardinality. Thus young knowledge workers' ordinal consideration of numbers, we suspect, may have a tinge of cardinality. This could be the possible 
reason of startling resemblance in the significance levels of estimates of two different analyses mentioned above in the tables of ordered probit and OLS regression. This subconscious shift of young knowledge workers towards exactitude (ordinal cardinality of numbers) may have some positive conviction to what we intend to investigate (i.e. to what extent young knowledge workers' assessment is reliable?).

A resemblance of highest degree regarding the levels of significance (in coefficient estimates in the two models) is remarkable. Logically, it permits us to rely upon the outputs given by the OLS regression as well, which is not advised to rely upon under customary circumstances i.e. the type and the set of variables we are dealing with. Hence, the uniqueness of our case is statistically proven and established. This surprising similarity in the levels of significance of the two analyses encourages us to rely upon the results of OLS regression with relatively greater confidence. We can proceed to calculate ANOVA; and we think, apparently, there is no harm at all in doing so. Anyhow, we are looking forward for some insight from other researchers who might have interest in such analyses.

We think that some deeper insight is required to compare coefficient estimates of ordered probit and OLS regressions. This is not our main concern here. This could be of interest for statisticians and econometricians. Any contribution in this regard will be of high value, we believe. We propose this venture to the adventurous researchers.

\section{Discussion}

Monthly Income has been reconstructed as an ordinal variable; initially, it was continuous variable. As it is an objective parameter so we can rely upon it more confidently (compared with the other two variables included in the analysis) for required level of competences declared by the young knowledge workers. We select a subcategory with lowest income i.e. Monthly Income 1 as a reference. The signs of the coefficient estimates allow the direction of change in the probabilities of the extreme outcomes only. Probabilities are relative to corresponding reference category. This subcategory contains young knowledge workers with lowest monthly income in our data set. The young knowledge workers who earn more than that of those in the reference category, ceteris paribus, have higher probability of having declared requisition of and a lower probability of not having declared requisition of greater level of almost all 12 competences in current job. By and large, monthly income coherently corresponds to the required level of competences. Theoretically, it is believed that higher requirement of competence level is better remunerated. Our results are in agreement to this belief. We have found coherence in theory and practice, which promotes also the suitability of the methodology we have employed. Unexpectedly, required level of competence 8 i.e. Mastery of your own field or discipline, contrary to other competences, reflected uneven coefficient estimates. This could be the case if job demands transversal (generic) competences more than the specific ones; and/or where higher salaries are not necessarily defined on the basis of specific competence [14] and [15].

Highly regular and coherent (in theory and practice) patterns are observed for the variable "Appropriate Education Level for Current Job". Young knowledge workers who declared that higher level education is required, ceteris paribus, have higher probability of having declared requisition of and a lower probability of not having declared requisition of greater level of almost all 12 competences in current job. Young knowledge workers who believe in lower education level as appropriate, ceteris paribus, have lower probability of having declared requisition of and a higher probability of not having declared requisition of greater level of almost all 12 competences in current job. In rather simple words we can say that young knowledge workers, who considered that higher education level (compared with reference category i.e. same education level) was appropriate for their current job, declared higher requirement of competence levels accordingly and vice versa.

Similarity in the levels of significance of the coefficients of ordered probit and OLS regression is observable for "Appropriate Education Level for Current Job".

Highly regular and coherent (in theory and practice) patterns are observed for the variable "Time to be Expert in Current Job". Young knowledge workers from subcategory ' 5 Years to be expert', ceteris paribus, have higher probability of having declared requisition of and a lower probability of not having declared requisition of greater level of almost all 12 competences in current job with respect to reference category i.e. 2 Years to be expert. Similar trends are observed for rest of two categories ' 10 Years to be expert' and 'More Years to be expert'.

We detect similarity in the levels of significance of the coefficients of ordered probit and OLS regression for "Time to be Expert in Current Job".

There is another side of the picture. Coherence could be marked easily in young knowledge workers' assessment at two different points of enquiry. This marked coherence lends reliability to young knowledge workers' responses all through the process of enquiry. If we take this subjective opinion reliable, it is interesting, however, that the young knowledge workers who followed more demanding study programmes have required higher level of certain competences. Truthfulness of this finding is favoured by virtue and convention. 
These observations are articulating what it is in theory as well as practice. We can say that veracity of these observations could be reliable as these are found consistent to what is expected theoretically and what is observed practically. These results ceteris paribus are coherent to what is expected theoretically and what we observe through our analyses.

Although a good discussion can be provoked regarding the interpretation of country and gender estimates mentioned in the tables, but we leave this for they are included in the model as control variables. Reader may look into them for their interest.

In fact we run two different models, namely, OLS and ordered probit regression, retaining same variables to see the explained variance by the independent variables. Unfortunately, the suitable estimation model, i.e. ordered probit model, according to the nature of the data, is mute to tell us the required information. Juxtaposition of the two outputs better help us to decide which direction we should move in. We find surprising similarity between the outputs of ordered probit regression and OLS regression. We are least concerned with the interpretation of the coefficient estimates of the later model; however, a resemblance of highest degree regarding the levels of significance (of coefficient estimates in the two models) is remarkable. Logically, it permits us to rely upon the outputs given by OLS regression as well, which is not advised to rely upon under usual circumstances with the type and set of variables we are dealing with. Hence, the uniqueness of our case is statistically proved and established. This surprising similarity between the levels of significance of two analyses encourages us to rely upon the results of OLS regression with relatively greater confidence.

\section{Conclusion}

This study discusses the reliability of assessment of required competences in the labour market by the young knowledge workers. We used Reflex data this study. We have exercised SPSS and Stata for statistical analyses.

We select three variables (income, time to be expert and appropriate education level) which appear to be closely related to the required competences. Assortment of competences has also been judiciously made. In order to see the effect of these three variables upon the requisition of competences we run ordered probit (and OLS regression as well for making a comparison).

We find coherence as well as consistency in the results. Momentarily, there was no contradiction traced. 'Appropriate education level' and 'time to be expert' reflected hierarchical order in the required levels of competences. Although these variables are subjective, yet, express a very regular behaviour in our analyses. As there is not oddity found, we may maintain that the young knowledge workers have rightly assessed their required levels of competences. It is true if we apply the criterion of falsifiability.

Income as an independent variable in our analyses offered an objective measure to respond to our question. It mirrored a highly regular hierarchical pattern. We may say that high required competence level corresponds to high income and vice versa. We found this through knowledge workers assessment of their required competences which is true in practical situation in the labour market. Again, applying the parameters of coherence and consistency, these findings relate that the assessment of required competences by the knowledge workers is reliable at least in Popperian terms. However we suggest further investigating this study competence-earning relationship in more detail with greater care. This is what we are going to present in the next study. Coming to our concern in this study, we are not reluctant to accept our alternative hypothesis because we cannot accept its null counterpart at all.

\section{$H_{A}$ : Knowledge workers of different subcategories do differ in their assessment of required competence level}

In conclusion, young knowledge workers' assessment of competence, modestly speaking, has been proved to be reliable. We could think and propose competence as a measure of Human Capital (HC). We encourage some investigation in this direction and we ourselves would like to do this, subjected to the opportunity. We do invite researchers for this venture. We think that competence could be a valid measure of $\mathrm{HC}$, but it is a long run objective. Anyhow it will be interesting to take the 'road not taken'.

\section{References}

Allen, J., \& van der Velden, R. (2005). The Role of Self-Assessment in Measuring Skills. REFLEX Working paper 2. http://www.reflexproject.org

Allen, J., \& van der Velden, R. (2005). The Role of Self-Assessment in Measuring Skills. REFLEX Working paper 2. $\mathrm{http}: / /$ www.reflexproject.org

Allen, J., \& van der Velden, R. (2005). The Role of Self-Assessment in Measuring Skills. REFLEX Working paper 2. http://www.reflexproject.org.) 
Borooah, V. K. (2001) Logit and Probit: ordered and multinomial Models. Sage University Papers Series on Quantitative Applications in the Social Sciences, 07-138. Thousand Oaks, CA: Sage.

Borooah, V. K. (2001). Logit and Probit: ordered and multinomial Models. Sage University Papers Series on Quantitative Applications in the Social Sciences, 07-138. Thousand Oaks, CA: Sage.

Büchel, F. (2002). The Effects of Overeducation on Productivity in Germany - The Firms' Viewpoint, Economics of Education

Dearing, R. (1997). Higher Education in the Learning Society, National Committee of Inquiry into Higher Education, Department of Education and Employment, London

García-Aracil, A., Mora, J.-G., \& Vila, L. E. (2004). The rewards of human capital competences for young European higher education graduates. Tertiary Education and Management, 10, 287-305. http://dx.doi.org/10.1080/13583883.2004.9967133

García-Aracil, A., Mora, J.-G., \& Vila, L. E. (2004). The rewards of human capital competences for young European higher education graduates. Tertiary Education and Management, 10, 287-305. http://dx.doi.org/10.1080/13583883.2004.9967133

Green, F. (2004). First Thoughts on Methodological Issues in an International Assessment of Adult Skills, Expert paper prepared for the first PIAAC IEG meeting, Paris, 26-27 April, OECD.

Green, F. (2004). First Thoughts on Methodological Issues in an International Assessment of Adult Skills, Expert paper prepared for the first PIAAC IEG meeting, Paris, 26-27 April, OECD.

Greene, W. H. (2000) Econometric Analysis (4 ${ }^{\text {th }}$ ed.). New Jersey: Prentice-Hall.

Heijke, H., \& Meng, C. (2006). The effects of higher education programme characteristics on allocation and performance of the graduates: a European view, (ROA-RM-2006/4E), Research Centre for Education and the Labour Market, Faculty of Economics and Business Administration, Maastricht University, Maastricht.

McFadden, D. (1973) Conditional Logit Analysis of Quantitative Choice Behavior. Frontiers in Econometrics, ed. By P. Zarambka. New York: Academic Press.

McFadden, D. (1973). Cgnditional Logit Analysis of Quantitative Choice Behavior. Frontiers in Econometrics, ed. By P. Zarambka. New York: Academic Press.

Nijhof, W.J. (1998). Qualifying for the Future, In: W.J. Nijhof \& J.N. Streumer. Key Qualifications in Work and Education, Dordrecht: Kluwer Academic Publishers, 19-38.

Teichler, U. (1999). Higher education policy and the world of work: changing conditions and challenges. Higher Education Policy, 12(4), 285-312. http://dx.doi.org/10.1016/S0952-8733(99)00019-7

Teichler, U. (1999). Higher education policy and the world of work: changing conditions and challenges. Higher Education Policy, 12(4), 285-312. http://dx.doi.org/10.1016/S0952-8733(99)00019-7 
Table 1. Percentages of variables of interest

\begin{tabular}{|c|c|c|c|}
\hline S. No. & Variable & $n$ & Percentage \\
\hline & \multicolumn{3}{|l|}{ Country } \\
\hline 1. & Austria & 1122 & 3.91 \\
\hline 2. & Belgium & 1049 & 3.66 \\
\hline 3. & Czech Republic & 5141 & 17.92 \\
\hline 4. & Estonia & 703 & 2.45 \\
\hline 5. & Finland & 1815 & 6.33 \\
\hline 6. & France & 1046 & 3.65 \\
\hline 7. & Germany & 1132 & 3.95 \\
\hline 8. & Italy & 1453 & 5.06 \\
\hline 9. & Japan & 1799 & 6.27 \\
\hline 10. & Netherlands & 2460 & 8.57 \\
\hline 11. & Norway & 1653 & 5.76 \\
\hline 12. & Portugal & 501 & 1.75 \\
\hline 13. & Spain & 2796 & 9.75 \\
\hline 14. & Switzerland & 4882 & 17.02 \\
\hline \multirow[t]{2}{*}{15.} & United Kingdom & 1138 & 3.97 \\
\hline & \multicolumn{3}{|c|}{\begin{tabular}{rl|l|} 
Total & $\mathbf{2 8 6 9 0}$ \\
\end{tabular}} \\
\hline & \multicolumn{3}{|l|}{ Total Monthly Income (in Euros) } \\
\hline 1. & Monthly Income 1 & 5796 & 20.81 \\
\hline 2. & Monthly Income 2 & 4140 & 14.86 \\
\hline 3. & Monthly Income 3 & 3924 & 14.09 \\
\hline 4. & Monthly Income 4 & 3453 & 12.40 \\
\hline 5. & Monthly Income 5 & 3028 & 10.87 \\
\hline 6. & Monthly Income 6 & 2268 & 8.14 \\
\hline 7. & Monthly Income 7 & 1543 & 5.54 \\
\hline \multirow[t]{2}{*}{8.} & Monthly Income 8 & 3699 & 13.28 \\
\hline & Total & 27851 & 100 \\
\hline & \multicolumn{3}{|c|}{ Appropriate Education Level for Current Job } \\
\hline 1. & Higher education level & 2680 & 9.51 \\
\hline 2. & Same education level & 20765 & 73.65 \\
\hline 3. & Low education level & 2577 & 9.14 \\
\hline \multirow[t]{2}{*}{4.} & Lower education level & 2171 & 7.70 \\
\hline & Total & 28193 & 100.00 \\
\hline & \multicolumn{3}{|c|}{ Time to be Expert in Current Job } \\
\hline 1. & 2 Years to be expert & 15713 & 55.73 \\
\hline 2. & 5 Years to be expert & 9140 & 32.41 \\
\hline 3. & 10 Years to be expert & 2463 & 8.73 \\
\hline \multirow[t]{2}{*}{4.} & More Years to be expert & 881 & 3.12 \\
\hline & Total & 28197 & 100.00 \\
\hline \multirow{4}{*}{$\begin{array}{l}1 . \\
2 .\end{array}$} & \multicolumn{3}{|l|}{ Gender } \\
\hline & Male & 12799 & 44.81 \\
\hline & Female & 15761 & 55.19 \\
\hline & Total & 28560 & 100.00 \\
\hline
\end{tabular}

Table 2. Basic statistics of variables of interest

\begin{tabular}{c|l|r|r|r} 
S. No. & \multicolumn{1}{|c|}{ Variable } & $n$ & \multicolumn{1}{|c}{$\bar{x}$} \\
\hline 1. & Country & 28690 & 8.774 & \multicolumn{1}{|c}{$\sigma$} \\
2. & Total Monthly Income (in Euros) & 27851 & 2348.418 & 1552.624 \\
3. & Appropriate Education Level for Current Job & 28193 & 2.150 & 0.687 \\
4. & Time to be Expert in Current Job & 28197 & 3.180 & 1.259 \\
5. & Gender & 28560 & 1.552 & 0.497 \\
\hline
\end{tabular}


Table 3. Decreasing mean values with respect to "Required Level of Competence"

\begin{tabular}{c|l|c|c|c} 
S. No. & \multicolumn{1}{|c|}{ Variable } & $n$ & $\bar{x}$ & \multicolumn{1}{c}{$\sigma$} \\
\hline $\mathbf{1 .}$ & Ability to use time efficiently & $\mathbf{2 5 8 4 6}$ & $\mathbf{5 . 5 7 8}$ & $\mathbf{1 . 3 2 6}$ \\
$\mathbf{2 .}$ & Ability to perform well under pressure & $\mathbf{2 5 8 5 1}$ & $\mathbf{5 . 5 5 3}$ & $\mathbf{1 . 4 0 3}$ \\
$\mathbf{3 .}$ & Ability to use computers and the internet & $\mathbf{2 5 8 5 1}$ & $\mathbf{5 . 4 4 9}$ & $\mathbf{1 . 4 5 3}$ \\
$\mathbf{4 .}$ & Ability to work productively with others & $\mathbf{2 5 8 4 6}$ & $\mathbf{5 . 4 1 4}$ & $\mathbf{1 . 4 3 6}$ \\
$\mathbf{5 .}$ & Ability to make your meaning clear to others & $\mathbf{2 5 8 4 3}$ & $\mathbf{5 . 3 8 2}$ & $\mathbf{1 . 3 7 1}$ \\
$\mathbf{6 .}$ & Ability to rapidly acquire new knowledge & $\mathbf{2 5 8 5 6}$ & $\mathbf{5 . 3 5 6}$ & $\mathbf{1 . 3 6 6}$ \\
$\mathbf{7 .}$ & Ability to coordinate activities & $\mathbf{2 5 8 4 2}$ & $\mathbf{5 . 3 5 0}$ & $\mathbf{1 . 4 3 5}$ \\
$\mathbf{8 .}$ & Mastery of your own field or discipline & $\mathbf{2 5 8 6 2}$ & $\mathbf{5 . 3 1 2}$ & $\mathbf{1 . 4 6 1}$ \\
$\mathbf{9 .}$ & Ability to write reports, memos or documents & $\mathbf{2 5 8 4 6}$ & $\mathbf{5 . 1 6 7}$ & $\mathbf{1 . 5 8 8}$ \\
$\mathbf{1 0 .}$ & Ability to come up with new ideas and solutions & $\mathbf{2 5 8 3 8}$ & $\mathbf{5 . 1 5 9}$ & $\mathbf{1 . 4 7 1}$ \\
$\mathbf{1 1 .}$ & Analytical thinking & $\mathbf{2 5 8 4 1}$ & $\mathbf{5 . 1 0 7}$ & $\mathbf{1 . 4 5 4}$ \\
$\mathbf{1 2 .}$ & Willingness to question your own and others' ideas & $\mathbf{2 5 8 4 3}$ & $\mathbf{4 . 9 4 2}$ & $\mathbf{1 . 4 7 4}$ \\
\hline 13. & Ability to mobilize the capacities of others & 25839 & 4.772 & 1.626 \\
14. & Ability to negotiate effectively & 25850 & 4.708 & 1.771 \\
15. & Ability to present products, ideas or reports to an audience & 25842 & 4.692 & 1.777 \\
16. & Alertness to new opportunities & 25817 & 4.659 & 1.636 \\
17. & Ability to assert your authority & 25845 & 4.650 & 1.662 \\
18. & Knowledge of other fields or disciplines & 25845 & 4.231 & 1.495 \\
19. & Ability to write and speak in a foreign language & 25386 & 3.894 & 2.132 \\
\hline
\end{tabular}

Reference Categories:

The Netherlands (for countries);

'Monthly Income 1 (up to $€ 1000.99$ )' for "Total Monthly Income (in Euros)";

'Same education level' for "Appropriate education level for current job";

'2 Years to be expert' for "Time to be expert in current job"; and

'Female' young knowledge workers for "Gender" 
Table 4. Coefficient estimates from ordered probit and OLS Regression

\begin{tabular}{|c|c|c|c|c|c|c|c|c|}
\hline & \multicolumn{2}{|c|}{ Competence 1} & \multicolumn{2}{|c|}{ Competence 2} & \multicolumn{2}{|c|}{ Competence 3} & \multicolumn{2}{|c|}{ Competence 4} \\
\hline & $\beta_{\text {oprobit }}$ & $\beta_{O L S}$ & $\beta_{\text {oprobit }}$ & $\beta_{\text {OLS }}$ & $\beta_{\text {oprobit }}$ & $\beta_{\text {OLS }}$ & $\beta_{\text {oprobit }}$ & $\beta_{\text {OLS }}$ \\
\hline Austria & $0.320^{\dagger \dagger}$ & $0.324^{\dagger \dagger}$ & $0.560^{\dagger \dagger}$ & $0.616^{\dagger \dagger}$ & $0.693^{\dagger \dagger}$ & $0.842^{\dagger \dagger}$ & $0.348^{\dagger \dagger}$ & $0.355^{\dagger \dagger}$ \\
\hline Belgium & 0.030 & 0.022 & $0.071^{*}$ & 0.065 & $0.104^{\dagger}$ & $0.129^{* *}$ & -0.021 & - 0.054 \\
\hline Czech Republic & $0.392^{\dagger \dagger}$ & $0.424^{\dagger \dagger}$ & $0.530^{\dagger \dagger}$ & $0.634^{\dagger \dagger}$ & $0.924^{\dagger \dagger}$ & $1.141^{\dagger \dagger}$ & $0.365^{\dagger \dagger}$ & $0.401^{\dagger \dagger}$ \\
\hline Estonia & $0.223^{\dagger \dagger}$ & $0.227^{\dagger \dagger}$ & $0.486^{\dagger \dagger}$ & $0.597^{\dagger \dagger}$ & $0.589^{\dagger \dagger}$ & $0.799^{\dagger \dagger}$ & $0.349^{\dagger \dagger}$ & $0.407^{\dagger \dagger}$ \\
\hline Finland & $0.129^{\dagger \dagger}$ & $0.126^{\dagger}$ & $0.171^{\dagger \dagger}$ & $0.191^{\dagger \dagger}$ & $0.387^{\dagger \dagger}$ & $0.501^{\dagger \dagger}$ & 0.020 & -0.012 \\
\hline France & $0.147^{\dagger \dagger}$ & $0.141^{\dagger}$ & $-0.072^{*}$ & $-0.198^{\dagger \dagger}$ & $0.074^{*}$ & 0.023 & $-0.093^{* *}$ & $-0.205^{\dagger \dagger}$ \\
\hline Germany & $0.288^{\dagger \dagger}$ & $0.301^{\dagger \dagger}$ & $0.518^{\dagger \dagger}$ & $0.583^{\dagger \dagger}$ & $0.359^{\dagger \dagger}$ & $0.436^{\dagger \dagger}$ & $0.186^{\dagger \dagger}$ & $0.180^{\dagger \dagger}$ \\
\hline Italy & $0.284^{\dagger \dagger}$ & $0.271^{\dagger \dagger}$ & $0.405^{\dagger \dagger}$ & $0.423^{\dagger \dagger}$ & $0.526^{\dagger \dagger}$ & $0.666^{\dagger \dagger}$ & $0.317^{\dagger \dagger}$ & $0.324^{\dagger \dagger}$ \\
\hline Japan & $0.229^{\dagger \dagger}$ & $0.214^{\dagger \dagger}$ & 0.038 & -0.011 & $0.301^{\dagger \dagger}$ & $0.375^{\dagger \dagger}$ & $0.159^{\dagger \dagger}$ & $0.141^{\dagger}$ \\
\hline Norway & $-0.162^{\dagger \dagger}$ & $-0.226^{\dagger \dagger}$ & -0.028 & -0.053 & -0.012 & -0.053 & $-0.258^{\dagger \dagger}$ & $-0.428^{\dagger \dagger}$ \\
\hline Portugal & $0.218^{\dagger \dagger}$ & $0.233^{\dagger \dagger}$ & $0.323^{\dagger \dagger}$ & $0.358^{\dagger \dagger}$ & $0.612^{\dagger \dagger}$ & $0.786^{\dagger \dagger}$ & $0.208^{\dagger \dagger}$ & $0.245^{\dagger \dagger}$ \\
\hline Spain & $0.202^{\dagger \dagger}$ & $0.208^{\dagger \dagger}$ & $0.206^{\dagger \dagger}$ & $0.210^{\dagger \dagger}$ & $0.299^{\dagger \dagger}$ & $0.388^{\dagger \dagger}$ & $0.219^{\dagger \dagger}$ & $0.198^{\dagger \dagger}$ \\
\hline Switzerland & $-0.056^{*}$ & $-0.136^{\dagger \dagger}$ & $0.189^{\dagger \dagger}$ & $0.195^{\dagger \dagger}$ & $0.243^{\dagger \dagger}$ & $0.296^{\dagger \dagger}$ & -0.031 & $-0.100^{* *}$ \\
\hline United Kingdom & $0.371^{\dagger \dagger}$ & $0.395^{\dagger \dagger}$ & $0.285^{\dagger \dagger}$ & $0.325^{\dagger \dagger}$ & $0.374^{\dagger \dagger}$ & $0.441^{\dagger \dagger}$ & $0.321^{\dagger \dagger}$ & $0.347^{\dagger \dagger}$ \\
\hline Monthly Income 2 & $0.082^{\dagger \dagger}$ & $0.104^{\dagger \dagger}$ & $0.139^{\dagger \dagger}$ & $0.192^{\dagger \dagger}$ & $0.077^{\dagger \dagger}$ & $0.105^{\dagger \dagger}$ & $0.125^{\dagger \dagger}$ & $0.176^{\dagger \dagger}$ \\
\hline Monthly Income 3 & $0.074^{\dagger}$ & $0.103^{\dagger \dagger}$ & $0.174^{\dagger \dagger}$ & $0.239^{\dagger \dagger}$ & $0.112^{\dagger \dagger}$ & $0.165^{\dagger \dagger}$ & $0.143^{\dagger \dagger}$ & $0.207^{\dagger \dagger}$ \\
\hline Monthly Income 4 & $0.132^{\dagger \dagger}$ & $0.184^{\dagger \dagger}$ & $0.281^{\dagger \dagger}$ & $0.392^{\dagger \dagger}$ & $0.193^{\dagger \dagger}$ & $0.295^{\dagger \dagger}$ & $0.200^{\dagger \dagger}$ & $0.295^{\dagger \dagger}$ \\
\hline Monthly Income 5 & $0.151^{\dagger \dagger}$ & $0.210^{\dagger \dagger}$ & $0.315^{\dagger \dagger}$ & $0.446^{\dagger \dagger}$ & $0.226^{\dagger \dagger}$ & $0.334^{\dagger \dagger}$ & $0.229^{\dagger \dagger}$ & $0.335^{\dagger \dagger}$ \\
\hline Monthly Income 6 & $0.147^{\dagger \dagger}$ & $0.199^{\dagger \dagger}$ & $0.351^{\dagger \dagger}$ & $0.483^{\dagger \dagger}$ & $0.240^{\dagger \dagger}$ & $0.356^{\dagger \dagger}$ & $0.227^{\dagger \dagger}$ & $0.335^{\dagger \dagger}$ \\
\hline Monthly Income 7 & $0.179^{\dagger \dagger}$ & $0.238^{\dagger \dagger}$ & $0.354^{\dagger \dagger}$ & $0.492^{\dagger \dagger}$ & $0.322^{\dagger \dagger}$ & $0.462^{\dagger \dagger}$ & $0.208^{\dagger \dagger}$ & $0.307^{\dagger \dagger}$ \\
\hline Monthly Income 8 & $0.260^{\dagger \dagger}$ & $0.345^{\dagger \dagger}$ & $0.446^{\dagger \dagger}$ & $0.609^{\dagger \dagger}$ & $0.371^{\dagger \dagger}$ & $0.529^{\dagger \dagger}$ & $0.278^{\dagger \dagger}$ & $0.416^{\dagger \dagger}$ \\
\hline Higher education level & $0.058^{\dagger}$ & $0.050^{*}$ & 0.020 & 0.020 & $0.111^{\dagger \dagger}$ & $0.135^{\dagger \dagger}$ & 0.017 & 0.015 \\
\hline Low education level & $-0.131^{\dagger \dagger}$ & $-0.170^{\dagger \dagger}$ & $-0.105^{\dagger \dagger}$ & $-0.160^{\dagger \dagger}$ & $-0.110^{\dagger \dagger}$ & $-0.151^{\dagger \dagger}$ & $-0.142^{\dagger \dagger}$ & $-0.200^{\dagger \dagger}$ \\
\hline Lower education level & $-0.349^{\dagger \dagger}$ & $-0.501^{\dagger \dagger}$ & $-0.237^{\dagger \dagger}$ & $-0.366^{\dagger \dagger}$ & $-0.425^{\dagger \dagger}$ & $-0.657^{\dagger \dagger}$ & $-0.275^{\dagger \dagger}$ & $-0.423^{\dagger \dagger}$ \\
\hline 5 Years to be expert & $0.104^{\dagger \dagger}$ & $0.132^{\dagger \dagger}$ & $0.104^{\dagger \dagger}$ & $0.138^{\dagger \dagger}$ & $-0.054^{\dagger \dagger}$ & $-0.065^{\dagger \dagger}$ & $0.073^{\dagger \dagger}$ & $0.101^{\dagger \dagger}$ \\
\hline 10 Years to be expert & $0.189^{\dagger \dagger}$ & $0.219^{\dagger \dagger}$ & $0.195^{\dagger \dagger}$ & $0.236^{\dagger \dagger}$ & $-0.134^{\dagger \dagger}$ & $-0.174^{\dagger \dagger}$ & $0.144^{\dagger \dagger}$ & $0.185^{\dagger \dagger}$ \\
\hline More Years to be expert & $0.220^{\dagger \dagger}$ & $0.214^{\dagger \dagger}$ & $0.251^{\dagger \dagger}$ & $0.276^{\dagger \dagger}$ & $-0.205^{\dagger \dagger}$ & $-0.297^{\dagger \dagger}$ & $0.203^{\dagger \dagger}$ & $0.240^{\dagger \dagger}$ \\
\hline Male & $-0.316^{\dagger \dagger}$ & $-0.372^{i \dagger}$ & $-0.174^{i \dagger}$ & $-0.202^{\dagger \dagger}$ & 0.005 & 0.007 & $-0.231^{\dagger \dagger}$ & $-0.287^{\dagger \dagger}$ \\
\hline$n$ & 28028 & 28028 & 28033 & 28033 & 28033 & 28033 & 28028 & 28028 \\
\hline (Pseudo) $R^{2}$ & 0.0158 & 0.0478 & 0.0140 & 0.0437 & 0.0253 & 0.0761 & 0.0116 & 0.0356 \\
\hline$L R \chi^{2}(26) / F$ & $1382.26^{\dagger \dagger}$ & $50.22^{\dagger \dagger}$ & $1249.12^{\dagger \dagger}$ & $45.73^{\dagger \dagger}$ & $2316.79^{\dagger \dagger}$ & $82.39^{\dagger \dagger}$ & $1069.67^{\dagger \dagger}$ & $36.89^{\dagger \dagger}$ \\
\hline
\end{tabular}

Values in bold - $(p>0.100)$ - No; * $(p \leq 0.100)$ - Marginal; ** - $(p \leq 0.050)$ - Fair; $\dagger$ - $(p \leq 0.010)$ - Good; †† - $(p \leq 0.001)$ Excellent 
Table 4. (continued) Coefficient estimates from ordered probit and OLS Regression

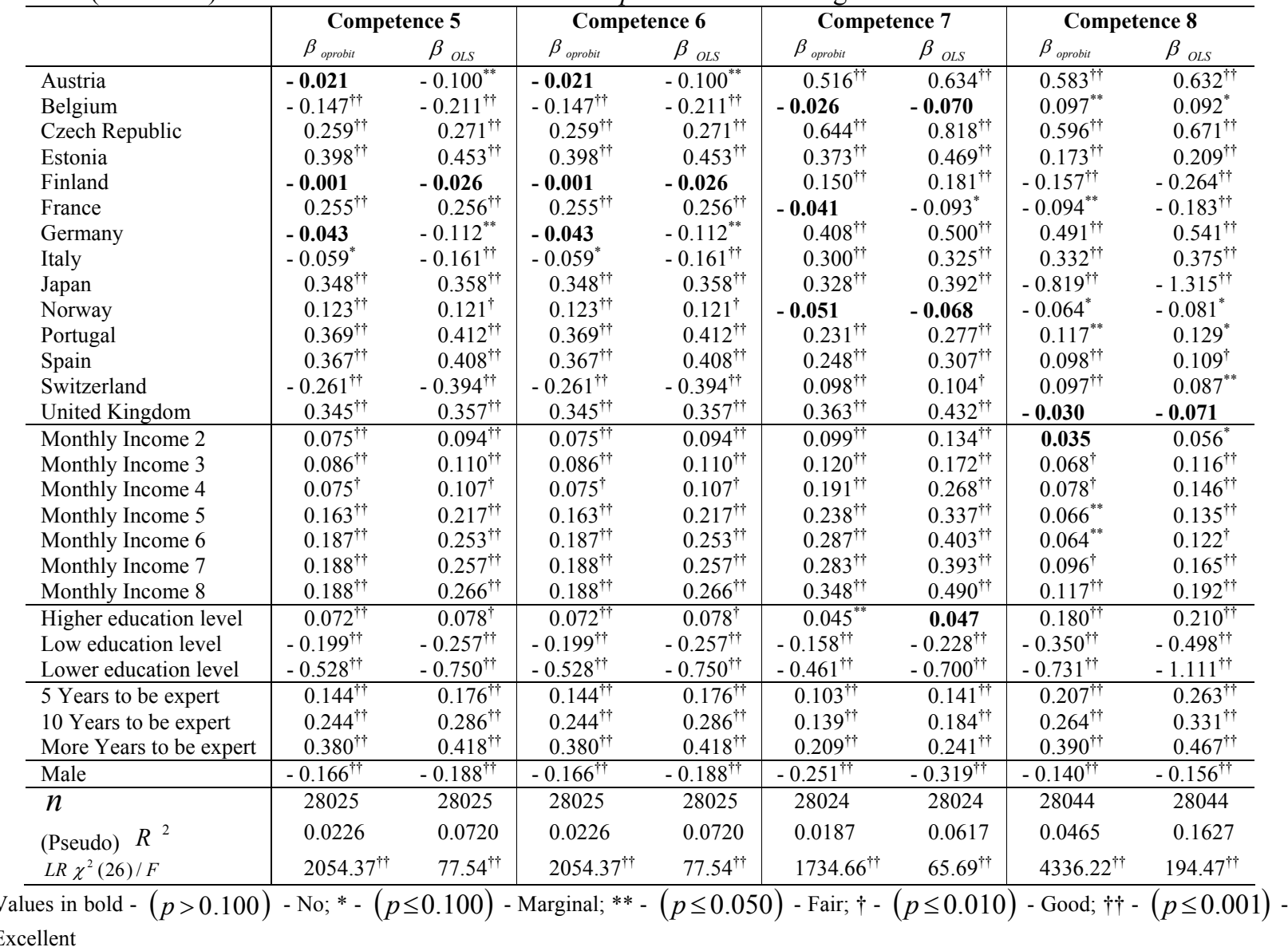


Table 4. (continued) Coefficient estimates from ordered probit and OLS Regression

\begin{tabular}{|c|c|c|c|c|c|c|c|c|}
\hline & \multicolumn{2}{|c|}{ Competence 9} & \multicolumn{2}{|c|}{ Competence 10} & \multicolumn{2}{|c|}{ Competence 11} & \multicolumn{2}{|c|}{ Competence 12} \\
\hline & $\beta_{\text {oprobit }}$ & $\beta_{o L S}$ & $\beta_{\text {oprobit }}$ & $\beta_{O L S}$ & $\beta_{\text {oprobit }}$ & $\beta_{o L S}$ & $\beta_{\text {oprobit }}$ & $\beta_{O L S}$ \\
\hline Austria & $0.429^{\dagger \dagger}$ & $0.583^{\dagger \dagger}$ & $0.189^{i \dagger}$ & $0.193^{i \dagger}$ & $0.401^{\dagger \dagger}$ & $0.460^{\dagger \dagger}$ & $-0.087^{* *}$ & $-0.182^{\dagger \dagger}$ \\
\hline Belgium & 0.059 & 0.074 & -0.023 & -0.056 & 0.039 & 0.025 & $-0.075^{* *}$ & $-0.130^{* *}$ \\
\hline Czech Republic & $0.737^{\dagger \dagger}$ & $1.042^{\dagger \dagger}$ & $0.260^{\dagger \dagger}$ & $0.303^{\dagger \dagger}$ & $0.566^{\dagger \dagger}$ & $0.736^{\dagger \dagger}$ & $0.374^{\dagger \dagger}$ & $0.468^{\dagger \dagger}$ \\
\hline Estonia & $0.331^{\dagger \dagger}$ & $0.447^{\dagger \dagger}$ & $0.322^{\dagger \dagger}$ & $0.392^{\dagger \dagger}$ & $0.525^{\dagger \dagger}$ & $0.681^{\dagger \dagger}$ & $-0.107^{* *}$ & $-0.187^{\dagger}$ \\
\hline Finland & $0.067^{* *}$ & 0.067 & $0.091^{\dagger}$ & $0.090^{* *}$ & $-0.064^{* *}$ & $-0.112^{\dagger}$ & $-0.071^{* *}$ & $-0.134^{\dagger}$ \\
\hline France & 0.007 & -0.031 & $-0.219^{\dagger \dagger}$ & $-0.369^{\dagger \dagger}$ & $0.198^{\dagger \dagger}$ & $0.243^{\dagger \dagger}$ & $-0.204^{\dagger \dagger}$ & $-0.329^{\dagger \dagger}$ \\
\hline Germany & $0.397^{\dagger \dagger}$ & $0.545^{\dagger \dagger}$ & $0.153^{\dagger \dagger}$ & $0.151^{\dagger}$ & $0.194^{\dagger \dagger}$ & $0.206^{\dagger \dagger}$ & -0.054 & $-0.124^{* *}$ \\
\hline Italy & $0.458^{\dagger \dagger}$ & $0.636^{\dagger \dagger}$ & $0.169^{\dagger \dagger}$ & $0.157^{\dagger \dagger}$ & $0.360^{\dagger \dagger}$ & $0.444^{\dagger \dagger}$ & $0.150^{\dagger \dagger}$ & $0.138^{\dagger}$ \\
\hline Japan & $0.488^{\dagger \dagger}$ & $0.703^{\dagger \dagger}$ & $0.304^{\dagger \dagger}$ & $0.345^{\dagger \dagger}$ & $0.325^{\dagger \dagger}$ & $0.400^{\dagger \dagger}$ & $0.158^{\dagger \dagger}$ & $0.169^{\dagger \dagger}$ \\
\hline Norway & $0.142^{\dagger \dagger}$ & $0.219^{\dagger \dagger}$ & $-0.242^{\dagger \dagger}$ & $-0.363^{\dagger \dagger}$ & $-0.487^{\dagger \dagger}$ & $-0.720^{\dagger \dagger}$ & $-0.242^{\dagger \dagger}$ & $-0.358^{\dagger \dagger}$ \\
\hline Portugal & $0.312^{\dagger \dagger}$ & $0.472^{\dagger \dagger}$ & 0.068 & 0.063 & $0.170^{\dagger \dagger}$ & $0.221^{\dagger \dagger}$ & - 0.034 & -0.069 \\
\hline Spain & $0.423^{\dagger \dagger}$ & $0.607^{\dagger \dagger}$ & $0.212^{\dagger \dagger}$ & $0.263^{\dagger \dagger}$ & $0.095^{\dagger}$ & $0.108^{\dagger}$ & -0.025 & -0.068 \\
\hline Swit & $0.262^{\dagger \dagger}$ & $0.371^{\dagger \dagger}$ & $-0.050^{*}$ & $-0.116^{\dagger}$ & $0.119^{\dagger \dagger}$ & $0.131^{\dagger \dagger}$ & $-0.146^{\dagger \dagger}$ & $-0.238^{\dagger \dagger}$ \\
\hline United Kingdom & $0.278^{\dagger \dagger}$ & $0.369^{\dagger \dagger}$ & $-0.097^{\dagger}$ & $-0.188^{\dagger \dagger}$ & -0.015 & -0.053 & -0.023 & -0.075 \\
\hline Monthly Income 2 & $0.053^{* *}$ & $0.088^{\dagger}$ & $0.069^{\dagger}$ & $0.101^{\dagger \dagger}$ & $0.119^{\dagger \dagger}$ & $0.160^{\dagger \dagger}$ & $0.057^{* *}$ & $0.089^{\dagger}$ \\
\hline Monthly Inc & $0.089^{\dagger \dagger}$ & $0.147^{\dagger \dagger}$ & $0.080^{\dagger \dagger}$ & $0.122^{\dagger \dagger}$ & $0.206^{\dagger \dagger}$ & $0.274^{\dagger \dagger}$ & $0.111^{\dagger \dagger}$ & $0.167^{\dagger \dagger}$ \\
\hline Mont & $0.182^{\dagger \dagger}$ & $0.298^{\dagger \dagger}$ & $0.104^{\dagger \dagger}$ & $0.167^{\dagger \dagger}$ & $0.228^{\dagger \dagger}$ & $0.316^{\dagger \dagger}$ & $0.133^{\dagger \dagger}$ & $0.208^{\dagger \dagger}$ \\
\hline Mont & $0.265^{\dagger \dagger}$ & $0.424^{\dagger \dagger}$ & $0.161^{\dagger \dagger}$ & $0.239^{\dagger \dagger}$ & $0.305^{\dagger \dagger}$ & $0.424^{\dagger \dagger}$ & $0.180^{\dagger \dagger}$ & $0.270^{\dagger \dagger}$ \\
\hline Month & $0.287^{\dagger \dagger}$ & $0.466^{\dagger \dagger}$ & $0.203^{\dagger \dagger}$ & $0.304^{\dagger \dagger}$ & $0.365^{\dagger \dagger}$ & $0.520^{\dagger \dagger}$ & $0.210^{\dagger \dagger}$ & $0.314^{\dagger \dagger}$ \\
\hline Month & $0.206^{\dagger \dagger}$ & $0.348^{\dagger \dagger}$ & $0.200^{\dagger \dagger}$ & $0.295^{\dagger \dagger}$ & $0.458^{\dagger \dagger}$ & $0.636^{\dagger \dagger}$ & $0.217^{\dagger \dagger}$ & $0.319^{\dagger \dagger}$ \\
\hline Monthly Income 8 & $0.192^{\dagger \dagger}$ & $0.324^{\dagger \dagger}$ & $0.160^{\dagger \dagger}$ & $0.247^{\dagger \dagger}$ & $0.438^{\dagger \dagger}$ & $0.620^{\dagger \dagger}$ & $0.179^{\dagger \dagger}$ & $0.271^{\dagger \dagger}$ \\
\hline Higher education level & $0.187^{\dagger \dagger}$ & $0.245^{\dagger \dagger}$ & $0.158^{\dagger \dagger}$ & $0.203^{\dagger \dagger}$ & $0.190^{\dagger \dagger}$ & $0.229^{\dagger \dagger}$ & $0.149^{\dagger \dagger}$ & $0.194^{\dagger \dagger}$ \\
\hline Low e & $-0.278^{\dagger \dagger}$ & $-0.428^{\dagger \dagger}$ & $-0.286^{\dagger \dagger}$ & $-0.400^{\dagger \dagger}$ & $-0.269^{\dagger \dagger}$ & $-0.365^{\dagger \dagger}$ & $-0.269^{\dagger \dagger}$ & $-0.381^{\dagger \dagger}$ \\
\hline Lower education level & $-0.740^{\dagger \dagger}$ & $-1.206^{\dagger \dagger}$ & $-0.647^{\dagger \dagger}$ & $-0.980^{\dagger \dagger}$ & $-0.727^{\dagger \dagger}$ & $-1.067^{\dagger \dagger}$ & $-0.622^{\dagger \dagger}$ & $-0.935^{\dagger \dagger}$ \\
\hline 5 Years to be expert & $0.111^{\dagger \dagger}$ & $0.171^{\dagger \dagger}$ & $0.106^{\dagger \dagger}$ & $0.142^{\dagger \dagger}$ & $0.149^{\dagger \dagger}$ & $0.202^{\dagger \dagger}$ & $0.141^{\dagger \dagger}$ & $0.196^{\dagger \dagger}$ \\
\hline 10 Years & $0.156^{\dagger \dagger}$ & $0.227^{\dagger \dagger}$ & $0.122^{\dagger \dagger}$ & $0.160^{\dagger \dagger}$ & $0.188^{\dagger \dagger}$ & $0.250^{\dagger \dagger}$ & $0.187^{\dagger \dagger}$ & $0.256^{\dagger \dagger}$ \\
\hline More Years to be expert & $0.214^{\dagger \dagger}$ & $0.278^{\dagger \dagger}$ & $0.157^{\dagger \dagger}$ & $0.179^{\dagger \dagger}$ & $0.200^{\dagger \dagger}$ & $0.237^{\dagger \dagger}$ & $0.280^{\dagger \dagger}$ & $0.360^{\dagger \dagger}$ \\
\hline Male & $-0.140^{\dagger \dagger}$ & $-0.172^{\dagger \dagger}$ & $-0.044^{\dagger \dagger}$ & $-0.052^{\dagger}$ & $0.082^{\dagger \dagger}$ & $0.122^{\dagger \dagger}$ & $-0.061^{\dagger \dagger}$ & $-0.073^{\dagger \dagger}$ \\
\hline$n$ & 28028 & 28028 & 28020 & 28020 & 28023 & 28023 & 28025 & 28025 \\
\hline (Pseudo) $R^{2}$ & 0.0252 & 0.0898 & 0.0171 & 0.0608 & 0.0314 & 0.1106 & 0.0189 & 0.0670 \\
\hline$L R \chi^{2}(26) / F$ & $2459.82^{\dagger \dagger}$ & $98.65^{\dagger \dagger}$ & $1640.77^{\dagger \dagger}$ & $64.66^{\dagger \dagger}$ & $3008.87^{\dagger \dagger}$ & $124.34^{\dagger \dagger}$ & $1840.52^{\dagger \dagger}$ & $71.80^{\dagger \dagger}$ \\
\hline
\end{tabular}

Values in bold - $(p>0.100)$ - No; * $(p \leq 0.100)$ - Marginal; ** - $(p \leq 0.050)$ - Fair; † - $(p \leq 0.010)$ - Good; †† - $(p \leq 0.001)$ Excellent

\section{Appendix A. Description of the Variables}

\section{Description of the Variables of Interest}

Required level of competences as a variable is our major concern in this study. This variable has been recorded on a 7-point rating scale ranging from very low (represented by 1) to very high (represented by 7). It is discrete and ordinal. Young knowledge workers were inquired to rate the level of competences required for their current job. It is pertinent to mention that they were inquired a few years after their graduation. Since the selected subset-I comprising 12 competences showed the required level of competences declared or believed by the young knowledge workers in their current job. The variables mentioned above are characteristic to current job.

\section{Total Monthly Income}

Total Monthly Income (in Euros) was continuous variable. We made the following eight subcategories.

Monthly Income 1 (up to $€ 1000.99$ ), Monthly Income 2 (€ 1001.00 - 1500.99), Monthly Income 3 (€ 1501.00 2000.99), Monthly Income 4 (€ 2001.00 - 2500.99), Monthly Income 5 (€ 2501.00 - 3000.99), Monthly Income 6 (€ 3001.00 - 3500.99), Monthly Income 7 (€ 3501.00 - 4000.99), Monthly Income 8 (€ 4001.00 - 4500.99)

Following is the excerpt from the Reflex Master Questionnaire asking about monthly income of the individuals.

\begin{tabular}{lll}
\hline F7 & What are your gross monthly earnings? & \\
\cline { 2 - 3 } & From contract hours in main employment & about \\
From overtime or extras in main employment & about \\
From other work & about
\end{tabular}

\section{Appropriate Education Level for Current Job}

Appropriate Education Level for Current Job has four subcategories.

Higher education level, Same education level, Low education level (lower level of tertiary education), Lower education level (below tertiary level) 
We present here the excerpt from the Reflex Master Questionnaire which is related to this variable.

\begin{tabular}{lll}
\hline F8 & $\begin{array}{l}\text { What type of education do you feel is most appropriate for this } \\
\text { work? }\end{array}$ & $\begin{array}{l}\text { PhD } \\
\text { other postgraduate qualification } \\
\text { master } \\
\text { bachelor } \\
\text { lower than higher education }\end{array}$ \\
& & \\
\end{tabular}

\section{Time to be Expert in Current Job}

Time to be Expert in Current Job was categorised into following four subcategories. We have merged first three subcategories into one: 2 Years to be expert (up to 2 years of experience), 5 Years to be expert (up to 5 years of experience), 10 Years to be expert (up to 10 years of experience), More Years to be expert (more than 10 years of experience)

Following is the excerpt from the Reflex Master Questionnaire for 'Time to be Expert in Current Job'.

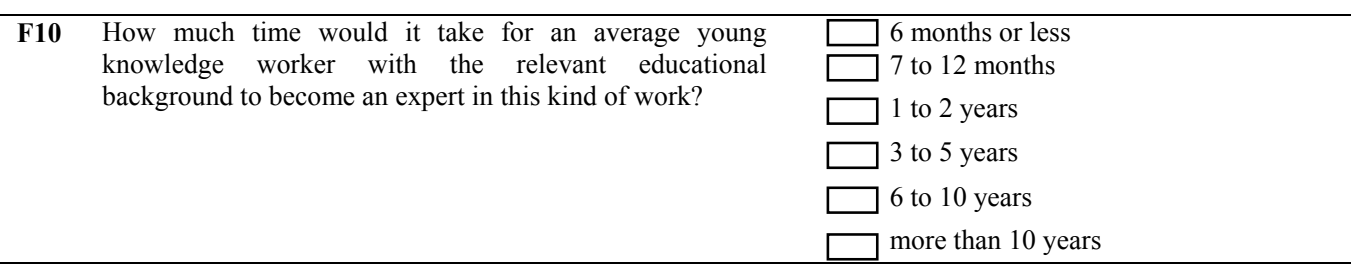

\section{Gender}

Here is the question about gender.

\section{Country}

\begin{tabular}{lll}
\hline K1 & Gender & $\square$ \\
& & $\begin{array}{l}\text { male } \\
\text { female }\end{array}$ \\
\hline
\end{tabular}

We have young knowledge workers from 15 countries in the data set we are using. Next section contains basic statistics concerning these variables.

\section{Competences}

Here is the list of 19 competences in section H1 of the Reflex Master Questionnaire (see the excerpt below). We are concerned with the B part of this question where required level in current work has been asked. Find the original excerpt of the questionnaire in the following.

\section{H1 Below is a list of competencies. Please provide} the following information:

. How do you rate your required level of competence?

. What is the required level of competence in your current work?

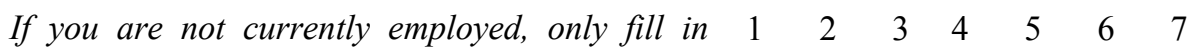
column A

a Mastery of your required field or discipline

b Knowledge of other fields or disciplines

c Analytical thinking

d Ability to rapidly acquire new knowledge

e Ability to negotiate effectively

f Ability to perform well under pressure

g Alertness to new opportunities

$\mathrm{h}$ Ability to coordinate activities

Ability to use time efficiently

Ability to work productively with others

Ability to mobilize the capacities of others

1 Ability to make your meaning clear to others
A Required level
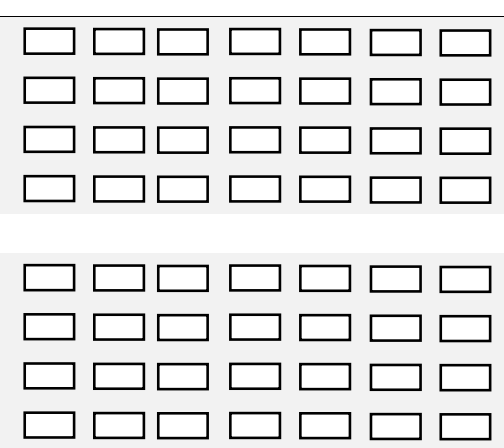

B Required level in current work

Very low $\longleftrightarrow$ very high

$\begin{array}{lllllll}1 & 2 & 3 & 4 & 5 & 6 & 7\end{array}$
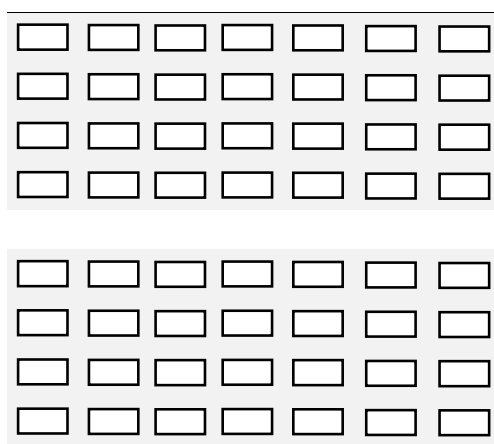
m $\quad$ Ability to assert your authority $\quad \square \square \square \square \square \square \square \square \square \square \square \square \square \square \square$

$\mathrm{n} \quad$ Ability to use computers and the internet

o Ability to come up with new ideas and solutions

$\mathrm{p} \quad$ Willingness to question your required and others' ideas
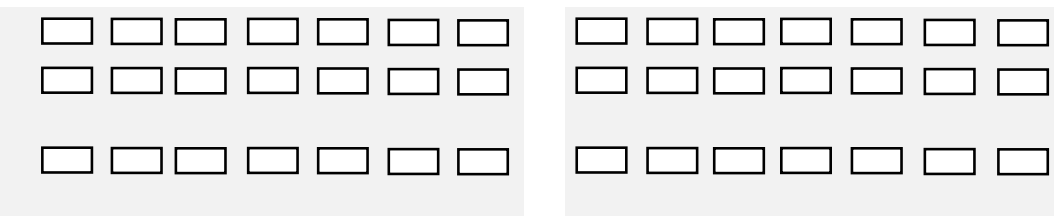

$\square \square \square \square \square \square \square$

$\square \square \square \square \square \square \square$ Others' ideas

q Ability to present products, ideas or reports to an audience

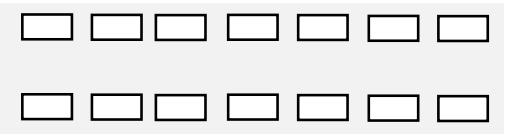

$\square \square \square \square \square \square \square$

$\mathrm{r} \quad$ Ability to write reports, memos or documents

s Ability to write and speak in a foreign

$\square \square \square \square \square \square \square$ language 